\title{
Early period maladaptive schemas, psycological symptoms and examining the tendency of deception
}

\author{
Kahraman Güler® \\ Department of Clinical Psychology, İstanbul Aydin University Faculty of Arts and Sciences, Istanbul, Turkey
}

\begin{abstract}
Objectives: There are relationships between early maladaptive schemas, psychological symptoms, and deception structures. Researches have not examined all these structures collectively in a single study. The aim of this study is to investigate the relationship between early maladaptive schemas, psychological symptoms and deception tendency according to various sociodemographic features. This research also aims to contribute to clinical studies. Many counselees who receive psychotherapy have problems in their relationships. Therefore, it is important to understand what is causing these problems.

Methods: The research was carried out with a total of 407 non-clinical participants, 200 women and 207 men who aged between 18 and 45 live in Istanbul. Data were collected from the participants using the Sociodemographic Information Form, the Young Schema Scale, the Brief Symptom Inventory, and the Deception Tendency Scale.

Results: According to the results of the applied correlation analyzes, it was found that there was a significant positive correlation between the components of early maladaptive schemas, psychological symptoms and infidelity tendency. The findings were interpreted and discussed within the framework of the literature.

Conclusions: An effective treatment plan can be developed that specifically addresses the etiological factor for problems that arise in close relationships. There is no significant positive relationship between the brief symptom inventory and the deception tendency scale. The base of this weak relationship is most likely to be associated with The Brief Symptom Inventory sub-dimensions of depression, anxiety, negative self, somatization, and hostility. We propose a research design to predict the relationship between EMS, personality, personality disorders, and the tendency of deception for other studies.
\end{abstract}

Keywords: Early maladaptive schemas, deception, close relationship, psychological symptom

$\mathrm{O}$ ur early childhood experiences occur our story and this story continues to resonate throughout our lives [1]. Early maladaptive schemas show up mostly in relational processes. Early maladaptive schemas (EMS) are pervasive life patterns that widely affect cognitions, emotions, memories, social perceptions, interactions, or behavioral patterns. EMS is being considered to developing during childhood. In this schema model, cognitive variables were accepted as key elements for understanding mental disorders [2]. Based on the assumptions of Beck's Cognitive Therapy [3], automatic thoughts, beliefs, and schemas influence emotions and behaviors. Therefore, it has been suggested that different cognitive levels contribute to the maintenance of different forms of psychopathology. Young et al. [4, 5], determined that the 
formation of cognitive schemas occurs in early childhood and extended Beck's original work by naming it with Early maladaptive schemas. EMS is elaborated during the childhood or adolescence and reenacted throughout life. It is also characterized as memories, emotions, and bodily sensations that contribute to a cognitive consistency about oneself or others [6]. EMS may increase or decrease throughout life depending on the person's individual coping mechanisms, life conditions, and interpersonal patterns. They often continue to exist because of these factors [7]. Schemas which are being grounded in childhood and adolescence are triggered by events in adulthood. These schemas play an important role in people's thoughts, feelings, behaviors, relationships with others, self-perceptions, and moods. This paradoxically leads a person to direct unintentionally recreate the conditions that hurt them in their childhood $[4,5]$. It seems that most of the problems between close relationships which are experienced are close relationships needs, spouse's needs, schemas, ways of dealing, and prisms which is composed with modes [6].

When we look at Young et al. [5] perspective of early maladaptive schemas, we can see that irrational, dysfunctional beliefs may lead to a view of unhealthy relationships and this may lead to reduced relationship satisfaction. Similarly, dysfunctional relationships with early age caregivers can predispose a person to hold beliefs about relationships and this care can tend to occur EMS's. As well as it leads to insecure attachment styles and specifically relationship loyalty problems.

People who have an insecure attachment style established with early caregivers are more likely to experience lower satisfaction in their relationships than people with a secure attachment style [8]. According to Harris and Curtin [9], conclude that certain EMS's are associated with negative affect and having negative core beliefs can predict depression or anxiety. It shows a relationship between EMS's and internalization problems in puberty including depression and anxiety $[2,10,11]$. EMS serves to guide later patterns of information processing and behavior that arise from early family interaction patterns. It is defined as stable and persistent dysfunctional beliefs about oneself in relation to the environment. Although there is no empirical link has been established between these EMS's, psychological symptoms, and the tendency of decep- tion, they have much in common with internal models of the attachment system. Also, schema theory shows that schemas which are known as schema modes and relevant relationship coping styles that establish dominance on self and different aspects of the self-show that how it separates from other aspects. The theory explains that how a person transitions among these things [12].

Deception involves various lies which show up the consequences of unfaithfulness inevitably or it involves discourses and behaviors which stay out of honesty borders [13]. Deception is the one of the most important factor which threats stability and survival of marriage and romantic relationship [14]. Concept of deception along with marriage is a part of violation of obligations which is regulated couples' relationships because of extramarital interaction. Also, it causes sanction deception may harbour sexual, emotional or both of them inside. The possibility of establishing an emotional relationship is higher for women. In marriage circumstances, sexual and emotional elements which are concomitant involve more threats than situations in which the only one exist [15]. Deception strongly affects the functioning and stability of the relationship [16]. There are lots of factors influence come into existence of unfaithfulness. For example, these include the nature of the relationship like dissatisfaction [17] and the context of the relationship such as opportunities and factors which related to being person including beliefs about love and gender [18].

There is a significant correlation with attachment style which involves deception, early maladaptive schemas, and emotional deprivation schemas. In Fricker's study [19], predicted that avoidant and anxious attachment and decepiton were highly correlated. The anxious attachment was found the correlation to be positively related to the list of extramarital behaviors and also, an avoidant attachment was correlated with a scale of propensity to deception. With regard to sexuality, a person's perception style of the sexual self is assumed to be closely linked to the individual's early attachment schemas. With the expanding attachment experiences that characterize adolescence and early adulthood, especially. Attachment behaviors in romantic relationships may be affected by sexual selfschemas which were developed during this period [20]. 


\section{Main Points}

1. All schema domains were positively associated with different severity of psychological symptoms, such as depression, anxiety, negative self, somatization, and hostility.

2. A positive and significant relationship was observed between unrelenting standards, insufficient self-control/ self dicipline schemas, and the tendency to deception.

3. The Dependence/ Incompetence and Defectiveness/ Shame schemas Abandonment/ Instability, Mistrust/Abuse, Social Isolation schemas were associated with the severity of depression.

4. Outpatients who were diagnosed with depression and without any clinical diagnosis found that Defectiveness/Shame, Insufficient Self-Control, and Self-Sacrifice schemas differed between those with and without a diagnosis of depression.

5. A certain event in an individual's life may trigger early maladaptive schemas that manifest themselves with the appearance of anxiety disorder or depression, depending on which schema is activated.

\section{METHODS}

\section{Universe and Sample}

In this study, 407 volunteer participants between the ages of 18-45 from the province of Istanbul took part. Participants, $49.1 \%$ were female, $50.9 \%$ male, $4.7 \%$ primary school graduate, $5.7 \%$ secondary school graduate, $14.3 \%$ high school graduate, $58.7 \%$ university graduate, $16.7 \%$ postgraduate or higher, $41.0 \%$ are married and $59.0 \%$ are single.

\section{Model of the Research}

In the research, "relational screening model" was used. Research designs aim to show the existence and/or degree of co-variation among more than one variable are defined as "a relational screening models".

\section{Data Collection}

Ethics committe approval of this study was obtained from Istanbul Aydin University. The data which was used in the research was collected in 2021. Sociodemographic Form, Young Schema Scale, the Brief Symptom Inventory, and Deception Tendency Scale were transferred to Google Forms in order to apply the data collection tools. In addition, it was distributed to 407 participants over the age of 18 who were selected by a simple random method. Data collection took approximately 40 days. It was explained to participants that do not need to give in information about their identities for answering data collection tools correctly and faithfully. When, the aim of research and data collection tools fill faithfully by participants, the reliability of research will increase. This situation is explained too.

\section{Data Collection Tools \\ Sociodemographic Data Form}

This is a personal data form consisting of gender, age, marital status, and educational status.

\section{Young Schema Scale}

The Turkish version of the Young Schema Questionnaire (YSS-SF3) (Young Schema Questionnaire YSQ-SF3) was used to measure the maladaptive schemas formed in the early period in the study. The Original Young Schema Scale (YSQ) is a scale consisting of 16 schemas and 205 items [5]. Later, a shorter form consisting of 15 schemes and 75 items was created (YSQ-SF 2) [21]. The Young Schema Scale Short Form-3 (YSQ-SF3) was created by adding Approval/Recognition-Seeking, Punitiveness, and Pessimism schemes to YSS-SF2 [5]. The validity and reliability study of the 90-item short form of the scale in our country was carried out by Soygüt et al [22] in a university sample. As a result of the analyzes which made to reveal the construct validity of the scale, it was seen that 16 schema dimensions were formed.

\section{Brief Symptom Inventory (BSI)}

The Brief Symptom Inventory is a Likert-type self-assessment inventory developed by Derogatis [23] upon the need for a short but valid and reliable scale to evaluate general psychopathology. The Brief Symptom Inventory is the short form of SCL-90-R that emerged as a result of studies with SCL-90-R. The reliability of the Brief Symptom Inventory was checked in the studies conducted by Şahin and Durak [24].

\section{Deception Tendency Scale}

The Deception Tendency Scale was developed by Polat [25] to evaluate the deception tendencies of mar- 
ried individuals and there are a total of 30 items on the scale.

\section{Statistical Analysis}

Statistical evaluations were analyzed using SPSS (Statistical Package for Social Sciences) 25.0 package program. The assumption of normal distribution, which is one of the first steps of the analysis, was checked. In this process, the kurtosis and skewness values of the scale and subscales were checked. When taking the study of George et al. [26] as a reference, these values are being in the reference range of $-2+2$ provides a normal distribution. By using Pearson Correlation analysis, the relationships between Young Schema Scale, the Brief Symptom Inventory, and Deception Tendency Scale were examined. The $p$ value which will be referenced is 0.05 and the confidence interval value is $95 \%$.

\section{RESULTS}

When we analyzed the findings, we found a middle level and positive relationship between Emotional
Deprivation and the Brief Symptom Inventory scores $(\mathrm{r}=.34, p<0.01)$, a weak and positive relationship between Emotional Deprivation and Anxiety scores ( $\mathrm{r}$ $=.30, p<0.01$ ), middle level and positive relationship between Emotional Deprivation and Depression scores $(\mathrm{r}=.35, p<0.01)$, middle level and positive relationship between Emotional Deprivation and Negative Self scores $(r=.39, p<0.01)$, weak and positive relationship between Emotional Deprivation and Instability scores $(\mathrm{r}=.22, p<0.01)$, a weak and positive relationship between Emotional Deprivation and Hostility scores $(\mathrm{r}=.25, p<0.01)$ (Table 1$)$.

Middle level and positive relationship between Social Isolation/Mistrust and the Brief Symptom Inventory scores $(r=.57, p<0.01)$, middle level and positive relationship between Social Isolation/Mistrust and Anxiety scores $(\mathrm{r}=.51, p<0.01)$, middle level and positive relationship between Social Isolation/Mistrust and Depression scores $(\mathrm{r}=.58, p<$ 0.01 ), middle level and positive relationship between Social Isolation/Mistrust and Negative Self scores ( $\mathrm{r}$ $=.63, p<0.01)$, middle level and positive relationship between Social Isolation/Mistrust and Instability scores $(\mathrm{r}=.34, p<0.01)$, and a middle level and pos-

Table 1. Relationships Between Young Schema Scale and The Brief Symptom Inventory

\begin{tabular}{lcccccc}
\hline & $\begin{array}{c}\text { The Brief Symptom } \\
\text { Inventory }\end{array}$ & Anxiety & Depression & $\begin{array}{c}\text { Negative } \\
\text { Self }\end{array}$ & Somatization & Hostility \\
\hline Emotional Deprivation & $.34^{* *}$ & $.30^{* *}$ & $.35^{* *}$ & $.39^{* *}$ & $.22^{* *}$ & $.25^{* *}$ \\
Social Isolation/Insecurity & $.57^{* *}$ & $.51^{* *}$ & $.58^{* *}$ & $.63^{* *}$ & $.34^{* *}$ & $.49^{* *}$ \\
\hline Defectiveness & $.41^{* *}$ & $.38^{* *}$ & $.41^{* *}$ & $.44^{* *}$ & $.28^{* *}$ & $.30^{* *}$ \\
Emotional Inhibition & $.46^{* *}$ & $.41^{* *}$ & $.43^{* *}$ & $.50^{* *}$ & $.33^{* *}$ & $.38^{* *}$ \\
\hline Nesting/Dependency & $.44^{* *}$ & $.40^{* *}$ & $.42^{* *}$ & $.48^{* *}$ & $.39^{* *}$ & $.28^{* *}$ \\
Abandonment & $.47^{* *}$ & $.44^{* *}$ & $.46^{* *}$ & $.53^{* *}$ & $.34^{* *}$ & $.35^{* *}$ \\
Vulnerability to Harm / & $.56^{* *}$ & $.53^{* *}$ & $.55^{* *}$ & $.59^{* *}$ & $.41^{* *}$ & $.43^{* *}$ \\
Illness & $.39^{* *}$ & $.37^{* *}$ & $.40^{* *}$ & $.40^{* *}$ & $.30^{* *}$ & $.26^{* *}$ \\
Failure & $.56^{* *}$ & $.54^{* *}$ & $.57^{* *}$ & $.52^{* *}$ & $.43^{* *}$ & $.45^{* *}$ \\
Pessimism & $.35^{* *}$ & $.31^{* *}$ & $.33^{* *}$ & $.37^{* *}$ & $.24^{* *}$ & $.33^{* *}$ \\
Self Dicipline /Insufficient & & & & & & $.22^{* *}$ \\
Self-Control & $.28^{* *}$ & $.26^{* *}$ & $.27^{* *}$ & $.31^{* *}$ & $.20^{* *}$ & $.22^{* *}$ \\
Self-Sacrifice & $.43^{* *}$ & $.41^{* *}$ & $.40^{* *}$ & $.44^{* *}$ & $.28^{* *}$ & $.37^{* *}$ \\
\hline Punitiveness & $.27^{* *}$ & $.25^{* *}$ & $.23^{* *}$ & $.31^{* *}$ & $.15^{* *}$ & $.25^{* *}$ \\
\hline Unrelenting Standards & $.38^{* *}$ & $.36^{* *}$ & $.37^{* *}$ & $.42^{* *}$ & $.25^{* *}$ & $.30^{* *}$ \\
\hline $\begin{array}{l}\text { Approval/Recognition } \\
\text { Seeking }\end{array}$ & & & & & & \\
\hline
\end{tabular}

$* * p<0.01, * p<0.05$ used test: Pearson Correlation Test 
itive relationship between Social Isolation/Mistrust and Hostility scores. $(r=.49, p<0.01)$ (see Table 1$)$.

Middle level and positive relationship between Defectiveness and the Brief Symptom Inventory scores $(\mathrm{r}=.41, p<0.01)$, middle level and positive relationship between Defectiveness and Anxiety scores $(\mathrm{r}=.38, p<0.01)$, middle level and positive correlation between Defectiveness and Depression scores ( $\mathrm{r}$ $=.41, p<0.01$ ), middle level and positive correlation between Defectiveness and Negative Self scores $(\mathrm{r}=$ $.44, p<0.01$ ), weak and positive relationship between the Defectiveness and Somatization scores $(\mathrm{r}=.28, p$ $<0.01$ ), weak and positive relationship between the Defectiveness and Hostility scores $(\mathrm{r}=.30, p<0.01)$ (see Table 1).

Middle level and positive relationship between Emotional Inhibition and the Brief Symptom Inventory scores $(\mathrm{r}=.46, p<0.01)$, Middle level and positive relationship between Emotional Inhibition and Anxiety scores $(\mathrm{r}=.41, p<0.01)$, Emotional Inhibition and Depression scores $(\mathrm{r}=.43, p<0.01)$ were middle level and positively correlated, Emotional Inhibition and Negative Self scores $(\mathrm{r}=.50, p<0.01)$ were middle level and positively correlated, Middle level and positive relationship between Emotional Inhibition and Somatization scores $(\mathrm{r}=.33, p<0.01)$, Middle level and positive relationship between Emotional Inhibition and Hostility scores $(\mathrm{r}=.38, p<0.01)$ (see Table 1).

Middle level and positive correlation between Incompetence/Dependence and the Brief Symptom Inventory scores $(\mathrm{r}=.44, p<0.01)$, middle level and positive between Incompetence/Dependence and Anxiety scores $(\mathrm{r}=.40, p<0.01)$, middle level and positive correlation between the scores of Incompetence/Dependence and Depression scores ( $\mathrm{r}$ $=.42, p<0.01)$, middle level and positive relationship between Incompetence/Dependence and Negative Self scores $(\mathrm{r}=.48, p<0.01)$, middle level and positive relationship between Incompetence/Dependence scores $(\mathrm{r}=.39, p<0.01)$, weak and positive correlation between the scores of Incompetence/Dependence and Hostility scores $(\mathrm{r}=.28, p<0.01)$ (see Table 1$)$.

Middle level and positive relationship between Abandonment and the Brief Symptom Inventory scores $(\mathrm{r}=.47, p<0.01)$, middle level and positive relationship between Abandonment and Anxiety scores $(\mathrm{r}=.44, p<0.01)$, middle level and positive relation- ship between Abandonment and Depression scores ( $\mathrm{r}$ $=.46, p<0.01$ ), middle level and positive relationship between Abandonment and Negative Self scores $(\mathrm{r}=$ .53, $p<0.01)$, middle level and positive correlation between Abandonment and Instability scores $(r=.34$, $p<0.01$ ), middle level and positive correlation between Abandonment and Hostility scores $(\mathrm{r}=.35, p<$ 0.01) (see Table 1).

Middle level and positive correlation between Vulnerability to Harm/Illness and the Brief Symptom Inventory scores $(\mathrm{r}=.56, p<0.01)$, middle level and positive correlation between Vulnerability to Harm/Illness and Anxiety scores $(\mathrm{r}=.53, p<0.01)$, middle level and positive correlation between Vulnerability to Harm/Illness and Depression scores $(\mathrm{r}=.55, p<0.01)$, middle level and positive correlation between Vulnerability to Harm/Illness and Negative Self scores ( $\mathrm{r}=$ $.59, p<0.01)$, middle level and positive correlation between Vulnerability to Harm/Illness and Instability scores $(\mathrm{r}=.41, p<0.01)$, middle level and positive correlation between Vulnerability to Harm/Illness and Hostility scores $(\mathrm{r}=.43, p<0.01)$ (see Table 1$)$.

Middle level and positive relationship between Failure and the Brief Symptom Inventory scores $(r=$ $.39, p<0.01)$, middle level and positive relationship between Failure and Anxiety scores $(\mathrm{r}=.37, p<0.01)$, middle level and positive relationship between Failure and Depression scores $(\mathrm{r}=.40, p<0.01)$, middle level and positive relationship between Failure and Negative Self scores $(\mathrm{r}=.40, p<0.01)$, middle level and positive relationship between Failure and Instability scores $(\mathrm{r}=.30, p<0.01)$, weak and positive relationship between Failure and Hostility scores $(\mathrm{r}=.26, p<$ 0.01) (see Table 1).

Middle level and positive correlation between Pessimism and the Brief Symptom Inventory scores $(\mathrm{r}=$ .56, $p<0.01)$, middle level and positive correlation between Pessimism and Anxiety scores $(\mathrm{r}=.54, p<$ 0.01 ), middle level and positive correlation between Pessimism and Depression scores $(\mathrm{r}=.57, p<0.01)$, middle level and positive correlation between Pessimism and Negative Self scores $(\mathrm{r}=.52, p<0.01)$, middle level and positive relationship between Pessimism and Instability scores $(\mathrm{r}=.43, p<0.01)$, middle level and positive relationship between Pessimism and Hostility scores $(\mathrm{r}=.45, p<0.01)$ (see Table 1$)$.

Middle level and positive relationship between Self Dicipline/Insufficient Self-Control and the Brief 
Symptom Inventory scores $(\mathrm{r}=.35, p<0.01)$, middle level and positive relationship between Self Dicipline/Insufficient Self-Control and Anxiety scores ( $\mathrm{r}$ $=.31, p<0.01$ ), middle level and positive correlation between Self Dicipline/Insufficient Self-Control and Depression scores $(r=.33, p<0.01)$, middle level and positive correlation between Self Dicipline/Insufficient Self-Control and Negative Self scores $(\mathrm{r}=.37, p$ $<0.01$ ), weak level and positive relationship between Self Dicipline/Insufficient Self-Control and Instability scores $(\mathrm{r}=.24, p<0.01)$, middle level and positive correlation between Self Dicipline/Insufficient SelfControl and Hostility scores $(r=.33, p<0.01)$ (see Table 1).

The weak and positive relationship between Self Sacrifice and the Brief Symptom Inventory scores ( $\mathrm{r}$ $=.28, p<0.01$ ), weak and positive relationship between Self-Sacrifice and Anxiety scores $(\mathrm{r}=.26, p<$ 0.01 ), weak and positive relationship between SelfSacrifice and Depression scores $(\mathrm{r}=.27, p<0.01)$, middle level and positive relationship between SelfSacrifice and Negative Self scores $(\mathrm{r}=.31, p<0.01)$, weak and positive relationship between Self-Sacrifice and Instability scores $(\mathrm{r}=.20, p<0.01)$, weak and positive relationship between Self-Sacrifice and Hostility scores $(\mathrm{r}=.22, p<0.01)$ (see Table 1$)$.

Middle level and positive relationship between Punitiveness and the Brief Symptom Inventory scores $(\mathrm{r}=.43, p<0.01)$, middle level and positive relationship between Punitiveness and Anxiety scores $(\mathrm{r}=.41$, $p<0.01$ ), middle level and positive relationship between Punitiveness and Depression scores $(\mathrm{r}=.40, p$ $<0.01$ ), middle level and positive relationship between Punitiveness and Negative Self scores $(\mathrm{r}=.44, p<$ 0.01 ), weak and positive relationship between Punitiveness and Instability scores $(\mathrm{r}=.28, p<0.01)$, middle level and positive relationship between Punitiveness and Hostility scores $(\mathrm{r}=.37, p<0.01)$ (see Table 1).

Weak and positive relationship between Unrelenting Standards and the Brief Symptom Inventory scores $(\mathrm{r}=.27, p<0.01)$, weak and positive relationship between Unrelenting Standards and Anxiety scores $(\mathrm{r}=$ $.25, p<0.01$ ), weak and positive relationship between Unrelenting Standards and Depression score $(\mathrm{r}=.23$, $p<0.01) \mathrm{s}$, middle level and positive relationship between Unrelenting Standards and Negative Self scores $(\mathrm{r}=.31, p<0.01)$, weak and positive relationship be- tween Unrelenting Standards and Instability scores ( $\mathrm{r}$ $=.15, p<0.01$ ), weak and positive relationship between Unrelenting Standards and Hostility scores $(\mathrm{r}=$ $.25, p<0.01)$ (see Table 1).

Middle level and positive correlation between Approval/Recognition Seeking and the Brief Symptom Inventory scores $(\mathrm{r}=.38, p<0.01)$, middle level and positive relationship between Approval/Recognition Seeking and Anxiety scores $(\mathrm{r}=.36, p<0.01)$, middle level and positive correlation between Approval/Recognition Seeking and Depression scores $(\mathrm{r}=.37, p<0.01)$, middle level and positive correlation between Approval/Recognition Seeking and Negative Self scores $(\mathrm{r}=.42, p<0.01)$, weak and positive relationship between Approval/Recognition Seeking and Instability scores $(\mathrm{r}=.25, p<0.01)$, middle level and positive correlation between Approval/Recognition Seeking and Hostility scores $(\mathrm{r}=.30, p<0.01)$ (see Table 1).

The weak and positive relationship between Deception Tendency Scale and Emotional Deprivation scores $(\mathrm{r}=.15, p<0.01)$, weak and positive relationship between Deception Tendency Scale and Social Isolation/Mistrust scores $(\mathrm{r}=.27, p<0.01)$, weak and positive relationship between Deception Tendency

Table 2. Relationships between Young Schema Scale and Deception Tendency Scale

\begin{tabular}{lc}
\hline & $\begin{array}{c}\text { Deception } \\
\text { Tendency Scale }\end{array}$ \\
\hline Emotional Deprivation & $.15^{* *}$ \\
\hline Social Isolation/Insecurity & $.27^{* *}$ \\
\hline Defectiveness & $.16^{* *}$ \\
\hline Emotional Inhibition & $.22^{* *}$ \\
\hline Incompetence/Dependence & $.16^{* *}$ \\
Abandonment & $.19^{* *}$ \\
\hline Vulnerability to Harm/IIlness & $.23^{* *}$ \\
\hline Failure & $.16^{* *}$ \\
\hline Pessimism & $.19^{* *}$ \\
\hline Self Dicipline /Insufficient Self- & $.30^{* *}$ \\
Control & .07 \\
Self-Sacrifice & $.13^{* *}$ \\
Punitiveness & $.33^{* *}$ \\
Unrelenting Standards & $.21^{* *}$ \\
\hline Approval / Recognition-Seeking & $T$. \\
\hline
\end{tabular}

$* * p<0.01, * p<0.05$ used test: Pearson Correlation Test 
Scale and Defectiveness scores $(\mathrm{r}=.16, p<0.01)$, weak and positive relationship between Deception Tendency Scale and Emotional Inhibition scores $(\mathrm{r}=$ $.22, p<0.01$ ), weak and positive relationship between Deception Tendency Scale and Incompetence/Dependence scores $(\mathrm{r}=.16, p<0.01)$, weak and positive relationship between Deception Tendency Scale and Abandonment scores $(\mathrm{r}=.19, p<0.01)$, weak and positive relationship between the Deception Tendency Scale and the Vulnerability to Harm/Illness scores ( $\mathrm{r}$ $=.23, p<0.01$ ), weak and positive relationship between the Deception Tendency Scale and Failure scores $(\mathrm{r}=.16, p<0.01)$, weak and positive relationship between Deception Tendency Scale and Pessimism scores $(r=.19, p<0.01)$, middle level and positive relationship between Deception Tendency Scale and Self Dicipline/Insufficient Self-Control scores $(\mathrm{r}=.30, p<0.01)$, weak and positive correlation between Deception Tendency Scale and Punitiveness scores $(\mathrm{r}=.13, p<0.01)$, middle level and positive relationship between Deception Tendency Scale and Unrelenting Standards scores $(\mathrm{r}=.33, p<$ 0.01 ), weak and positive correlation between Deception Tendency Scale and Approval/Recognition-Seeking scores $(\mathrm{r}=.21, p<0.01)$ (Table 2).

The weak and positive correlation between Deception Tendency Scale and the Brief Symptom Inventory scores $(\mathrm{r}=.23, p<0.01)$, weak and positive relationship between Deception Tendency Scale and Anxiety scores $(\mathrm{r}=.20, p<0.01)$, weak and positive correlation between Deception Tendency Scale and Depression scores $(\mathrm{r}=.21, p<0.01)$, weak and positive relationship between Deception Tendency Scale and

\section{Table 3. Relationships between the Brief Symptom Inventory and Deception Tendency Scale}

\begin{tabular}{lc}
\hline & $\begin{array}{c}\text { Deception } \\
\text { Tendency Scale }\end{array}$ \\
\hline The Brief Symptom Scale & $.23^{* *}$ \\
Anxiety & $.20^{* *}$ \\
Depression & $.21^{* *}$ \\
Negative Self & $.22^{* *}$ \\
Somatization & $.16^{* *}$ \\
Hostility & $.24^{* *}$ \\
\hline
\end{tabular}

${ }^{* *} p<0.01,{ }^{*} p<0.05$ used test: Pearson Correlation Test
Negative Self scores $(r=.22, p<0.01)$, weak and positive relationship between the Deception Tendency Scale and the Instability scores $(\mathrm{r}=.16, p<0.01)$, weak and positive relationship between the Deception Tendency Scale and Hostility scores $(\mathrm{r}=.24, p<0.01)$ (Table 3).

\section{DISCUSSION}

The research was made to examine the relationship between early maladaptive schemas, psychological symptoms, and deception with each other. To reach research findings, the research was made on 407 non-clinical volunteer participants aged between 1845 from the province of Istanbul. Also, these findings are being argued with literature.

The severity of the relationship between EMS and psychological symptoms and the relationship between these structures and the tendency to deception were evaluated. In the non-clinical sample, all schema domains were positively associated with different severity of psychological symptoms, such as depression, anxiety, negative self, somatization, and hostility. According to the research findings, emotional deprivation, social isolation/mistrust, defectiveness, emotional deprivation, abandonment, vulnerability to harm/illness, pessimism, dependence/incompetence were found to be significantly positively correlated with the severity of EMS and depression, anxiety, and negative self-perception symptoms. Vulnerability to harm/illness, pessimism, social isolation/mistrust is significantly positively associated with EMS and somatization and hostility. These findings are compatible with van Genderen [27] relationship between depressive personality structure and social isolation/mistrust, defectiveness/shame, vulnerability to harm/illness, pessimism, and failure schemas. A study conducted by Shah and Waller [28] on a sample of outpatients who were diagnosed with depression and without any clinical diagnosis found that Defectiveness/Shame, Insufficient Self-Control, and SelfSacrifice schemas differed between those with and without a diagnosis of depression.

In studies conducted with a sample of non-clinical individuals, the Dependence/Incompetence and Defectiveness/Shame schemas [29], Abandonment/Instability, Mistrust/Abuse, Social Isolation [9] schemas 
were associated with the severity of depression. The findings of these studies and the findings that have not been researched show compatibility.

A certain event in an individual's life may trigger early maladaptive schemas that manifest themselves with the appearance of anxiety disorder or depression, depending on which schema is activated. For example, an individual with the Vulnerability to Harm/Illness schema will be more likely to show signs of anxiety disorder than to show signs of depression [30-32] evaluate those personality traits as inherited tendencies that influence the actions of early caregivers. The repetitive dysfunctional behaviors of early caregivers contribute to the development of unconditioned, negative self, others, and worldviews. This EMS can cause personality problems in several ways. First, the experience of these belief systems can trigger depressive, anxiety, or anger symptoms. Secondly, EMS may predispose individuals to seek problematic close, social, and professional relationships that reinforce the power of the schema. Thirdly, when the experience of affectivity and memories which be associate with EMS is troubled, individuals develop maladaptive coping styles including avoidance [30].

In our research findings, the positive relationship between emotional deprivation, social isolation/mistrust, defectiveness, emotional deprivation, abandonment, vulnerability to harm/illness, pessimism, dependence/incompetence, and the severity of EMS with depression, anxiety, and negative self-perception symptoms a consistent with Young's [30] explanations. There is a theoretical link between EMS and psychopathology. EMS is mediating variable which takes a turn on the relationship between adult psychopathology and negative childhood experiences [33].

In our research findings, a positive and significant relationship was observed between unrelenting standards, insufficient self-control/self sicipline schemas, and the tendency to deception. The significant positive relationship between the tendency to deception and unrelenting standards seems contradictory at first glance. Unrelenting standards are characterized by inflexible rules which are including unrealistic moral, ethical and cultural, religious instructions in many areas of life, perfectionism, excessive attention to detail, and underestimation of one's performance compared to the norm [6].
However, this always involves a deterioration in the areas of enjoyment, relaxation, health, self-esteem, perception of success, and satisfying relationships. On the other hand, the insufficient self-control/self dicipline schema involves the individual having a pervasive difficulty or refusal to maintain adequate self-control and tolerate frustration to achieve personal goals and to restrain overexpression of emotions and impulses. People who have this schema do not exhibit sufficient self-control. They cannot show tolerance for disappointment. If they cannot achieve their individual goals, and they have difficulty in regulating their emotions and impulse expressions. Those who have this schema at a milder level show avoidance of pain, conflict, challenge, responsibility or they make exaggerated efforts in matters of personal satisfaction, commitment, and integrity [4].

\section{CONCLUSION}

The research was made to examine the relationship between early maladaptive schemas, psychological symptoms, and deception with each other. Outpatients who were diagnosed with depression and without any clinical diagnosis found that Defectiveness/Shame, Insufficient Self-Control, and Self-Sacrifice schemas differed between those with and without a diagnosis of depression. The severity of the relationship between EMS and psychological symptoms and the relationship between these structures and the tendency to deception were evaluated. An effective treatment plan can be developed that specifically addresses the etiological factor for problems that arise in close relationships. There is no significant positive relationship between the brief symptom inventory and the deception tendency scale. The base of this weak relationship is most likely to be associated with the Brief Symptom Inventory sub-dimensions of depression, anxiety, negative self, somatization, and hostility. We propose a research design to predict the relationship between EMS, personality, personality disorders, and the tendency of deception for other studies.

\section{Authors' Contribution}

Study Conception: KG; Study Design: KG; Supervision: KG; Funding: KG; Materials: KG; Data Collection and/or Processing: KG; Statistical Analysis 
and/or Data Interpretation: KG; Literature Review: KG; Manuscript Preparation: KG and Critical Review: $\mathrm{KG}$.

\section{Conflict of interest}

The authors disclosed no conflict of interest during the preparation or publication of this manuscript.

\section{Financing}

The authors disclosed that they did not receive any grant during conduction or writing of this study.

\section{Ethics Committee Approval}

Ethics committee aproval was received fort his study from the Istanbul Aydin University (Approval Date: June 9, 2021; Approval Number:2021/7).

\section{Informed Consent}

Written informed consent was obtained from the individuals who participated in this study.

\section{REFERENCES}

1. Skeen M. Love Me, Don't Leave Me: Overcoming Fear of Abandonment and Building Lasting, Loving Relationships. Ankara: KPA Publication; 2019.

2. Calvete E, Orue I, Hankin, BL. A longitudinal test of the vulnerability- stress model with early maladaptive schemas for depressive and social anxiety symptoms in adolescents. J Psychopathol Behav Assess 2015;37:85-99.

3. Hofmann S, Asmundson GJG, Beck AT. The science of cognitive therapy. Behav Ther 2013; 44:199-212.

4. Young JE, Klosko JS. Reinventing Your Life. (S. Kohen ve D. Güler, Çev) İstanbul: Psikonet Publication; 2013.

5. Young JE, Kolosko JS, Weishaar ME. Schema Therapy. T. Özakkaş (Ed.), (T.V. Soylu, Çev.) İstanbul: Litera Publication; 2009.

6. Rafaeli E, Bernstein DP, Young JE. Schema Therapy: Distinctive Features. New York, NY US: Routledge Taylor \&Francis Group; 2011.

7. Arntz A, Jacob G. Schema Therapy in Practice: An Introductory Guide to the Schema Mode Approach. Ankara: Nobel Akademic Publication; 2016.

8. Simpson JA. Influence of attachment styles on romantic relationships. J Pers Soc Psychol 1990;59:971-80.

9. Harris AE, Curtin L. Parental perceptions, early maladaptive schemas and depressive symptoms in young adults. Cognit Ther Res 2002;26:405-16.

10. Calvete E. Emotional abuse as a predictor of early maladaptative schemas in adolescents: contributions to the development of depressive and social anxiety symptoms. Child Abuse Negl 2014;38:735-46.
11. Mateos-Pérez E, Calvete E, Hankin BL. Negative inferences as mediators of the predictive association between early maladaptive schemas and depressive symptoms in adolescents. J Soc Clin Psychol 2015;34:259-76.

12. Safran JD. Toward a refinement of cognitive therapy in light of interpersonal theory: I. Theory. Clin Psychol Rev 1990;10:87105.

13. Sungur MZ. Love, Marriage, Marital Infedility. Devil's Triangle. İstanbul: Destek Publication; 2021.

14. Mark KP, Janssen E, Milhausen RR. Infidelity in heterosexual couples: demographic, interpersonal, and personality-related predictors of extradyadic sex. Arch Sex Behav 2011;40:971-82.

15. Simeone-DiFrancesco C, Roediger E, Stevens BA. Schema therapy with couples: a practitioner's guide to healing relationships. Wiley-Blackwell; 2015.

16. Drigotas SM, Safstrom CA, Gentilia T. An investment model prediction of dating infidelity. J Pers Soc Psychol 1999;77:50924.

17. Atkins DC, Jacobson NS, Baucom DH. Understanding infidelity: correlates in a National Random Sample. J Fam Psychol 2001;15:735-49.

18. Wiederman MW, Hurd C. Extradyadic involvement during dating. J Soc Pers Relat 1999;16:265-74.

19. Fricker J. Predicting infidelity: The role of attachment styles, lovestyles, and the investment model. Doctorate Thesis, Swinburne University of Technology; 2006.

20. Cranowski JM, Anderson BL. Schemas, sexuality, and romantic attachment. J Pers Soc Psychol 1998;74:1364-79.

21. Cecero JJ, Nelson JD, Gillie JM. Tools and tenets of schema therapy: toward the construct validity of the early maladaptive schema questionnaire-research version (EMSQ-R). Clin Psychol Psychother 2004;11:344-57.

22. Soygüt G, Karaosmanoğlu A, Çakır Z. [Assessment of Early Maladaptive Schemas: A Psychometric Study of the Turkish Young Schema Questionnaire-Short Form-3]. Türk Psikiyatri Dergisi 2009;20:75-84. [Article in Turkish]

23. Derogatis LR. SCL-90-R: Administration, Scoring \& Procedures Manual-II, for the R (Revised) Version and Other Instruments of the Psychopathology Rating Scale Series. 2nd Edition, Clinical Psychometric Research J, Inc., Towson; 1992.

24. Şahin N, Durak A. [A study of the Brief Symptom Inventory in Turkish Youth]. Turkish Psychology Journal 1994;9:44-56. [Article in Turkish]

25. Polat D. A Research of the Relationships Between Marriage Adjustments, Cheating Tendencies and Conflict Tendencies of Married Individuals in Terms of Some Variables. Unpublished Master Thesis Ankara: Ankara University; 2006.

26. George D, Mallery P. SPSS for Windows Step by Step: A Simple Guide and Reference 17.0 Update. 10th Ed., Boston: Allyn \& Bacon; 2010.

27. Arntz A, van Genderen H. Schema therapy for borderline personality disorder. (Drost J: Trans.). Wiley-Blackwell; 2009.

28. Shah R, Waller G. Parental style and vulnerability to depression: the role of core beliefs. J Nerv Ment Dis 2000;188:19-25. 29. Schmidt NB, Joiner TE, Young JE, Telch MJ. The schema questionnaire: investigation of psychometric properties and the hierarchical structure of a measure of maladaptive schemas. Cog- 
nit Ther Res 1995;19:295-321.

30. Young JE. Cognitive therapy for personality disorders: a schema-focused approach. 3rd ed., Sarasota, FL: Professional Resource Exchange Inc; 1994.

31. Ball SA, Young JE. Dual focus schema therapy for personality disorders and substance dependence: case study results. Cognit Behav Pract 2000;7:270-81.
32. Ball SA, Cecero JJ. Addicted patients with personality disorders: traits, schemas, and presenting problems. J Pers Disord 2001;15:72-83.

33. Carr SN, Francis AJP. Early maladaptive schemas and personality disorder symptoms: an examination in a non-clinical sample. Psychol Psychother 2010;83:333-49. 